\section{Emergence of Honey Mesquite Seedlings Relative to Planting Depth and Soil Temperature ${ }^{1}$}

\section{J. SCIFRES 2 AND J. H. BROCK}

Assistant Professor and Research Associate, Texas A $\leftrightarrow M$ University Agricultural Research and Extension Center, Lubbock.

\section{Highlight}

Maximum emergence occurred when honey mesquite (Prosopis glandulosa Torr, var. glandulosa) seeds were planted $0.5 \mathrm{~cm}$ deep at a soil temperature of $27 \mathrm{C}$. Percent emergence was severely reduced at a soil temperature of $18 \mathrm{C}$, regardless of planting depth. Seeds placed on the soil surface germinated, but seedlings did not survive. Seeds planted 5 to $6 \mathrm{~cm}$ deep germinated, but no seedlings emerged. Rate and extent of emergence in a nursery were evidently dependent on the temperature reaching $24 \mathrm{C}$ in the surface $2.5 \mathrm{~cm}$ of soil.

Honey mesquite (Prosopis glandulosa Torr. var. glandulosa) infests about 55 million acres of rangeland in Texas (Allred, 1949). It invades rangelands varying in range condition class, soils and climate (Fisher et al., 1959).

Honey mesquite seeds are borne in a legume with a rigid endocarp (Meyer et al., 1971). The protective covering of the legume and the highly sclerified testa probably attributes to longevity of viable Prosopis seeds in storage (Martin, 1948) and in soil (Tschirley and Martin, 1960). Production of large quantities of seed by honey mesquite results in continuous seed supplies in the soil (Fisher et al., 1959). However, only a small percentage produce mature trees under natural conditions (Scifres et al., 1971). Establishment of honey mesquite is not necessarily correlated with high annual or average seasonal precipitation. The short period of time from germination to seedling establishment must strongly influence success of honey mesquite ecesis, since established seedlings can readily replace topgrowth (Scifres and Hahn, 1971) and may withstand considerable environmental stress (Meyer et al., 1971). Germination with minimal ambient moisture partially explains the adaptability of honey mesquite to semiarid conditions (Scifres and Brock, 1969). However, ambient temperature is also important since it regulates rate and extent of moisture uptake by germinating honey mesquite seeds (Scifres and Brock, 1971).

The objective of this study was to investigate

\footnotetext{
${ }^{1}$ Approved by the Director, Texas Agricultural Experiment Station as TA-9157. Received May 6, 1971.

${ }^{2}$ Present address of C. J. Scifres is Department of Range Science, Texas A\&M University, College Station.
}

the regulation of honey mesquite emergence by planting depth and soil temperature. Experimental data arc correlated with results from other studies in an effort to elucidate optimum environmental conditions for establishment of honey mesquite seedlings.

\section{Materials and Methods}

In four greenhouse experiments, Abilene silty clay loam was added to $946 \mathrm{cc}$ containers (15-cm diameter) and packed to a bulk density of approximately 1.1. Twenty scarified honey mesquite seeds with laboratory germination of over $95 \%$ were planted on the soil surface and at $0.5 \mathrm{~cm}$ increments to a depth of $6 \mathrm{~cm}$. Soil temperature was maintained at $27 \mathrm{C}$ and monitored with recording hygrothermographs. In two additional experiments, honey mesquite seeds were planted in soil at a temperature of $18 \mathrm{C}$. Each planting depth was replicated four or five times, and all experiments were arranged in randomized complete block designs. At 3-day intervals, the number of emerged seedlings was recorded. After 21 days, seedlings were washed free of soil and shoot and root lengths recorded.

Honey mesquite seeds were planted February 27 and at weekly intervals until May 1, 1969 in a nursery in the Rolling Plains of Texas. The soil was an Abilene silty clay loam and temperatures were monitored with recording hygrothermographs at $2.5,7.5$ and $15 \mathrm{~cm}$ deep from February 27 to May 15, 1969. Fifty honey mesquite seeds were planted in the surface $\mathrm{cm}$ of soil in each of three rows, 4.5 $\mathrm{m}$ long and $0.5 \mathrm{~m}$ apart, arranged in a randomized complete block design. The nursery was watered as needed to insure seed germination when soil temperature had reached optimum levels and durations. Periodically, the number of honey mesquite seedlings per row, leaves per plant, plant heights, and nodes per stem were recorded.

\section{Results and Discussion}

Germination of honey mesquite seeds was rapid in the greenhouse and the radicle was apparent two days after planting. By the sixth day, cotyledons were fully expanded, and the epicotyl was prominent.

Honey mesquite seeds germinated on the soil surface, but seedlings did not establish (Fig. 1). Other studies have shown that honey mesquite seeds germinate readily in light or dark (Scifres and Brock, 1969) so it is assumed that germination in these studies was not confounded by photoperiod. Honey mesquite seedling emergence was highest from planting depths of 0.5 to $1.5 \mathrm{~cm}$ and a soil temperature of $27 \mathrm{C}$ (Fig. 1). No seedlings emerged from planting depths of 5 to $6 \mathrm{~cm}$. Emergence was poor at $18 \mathrm{C}$ soil temperature regardless of planting depth.

Average time required for honey mesquite seedling emergence at $27 \mathrm{C}$ increased with planting depth (Fig. 1). Delayed emergence was reflected in reduced seedling vigor. There was a direct relationship between total seedling length and planting depth. The longest seedlings (root + shoot) emerged from the 0.5 or $1-\mathrm{cm}$ planting depths. 

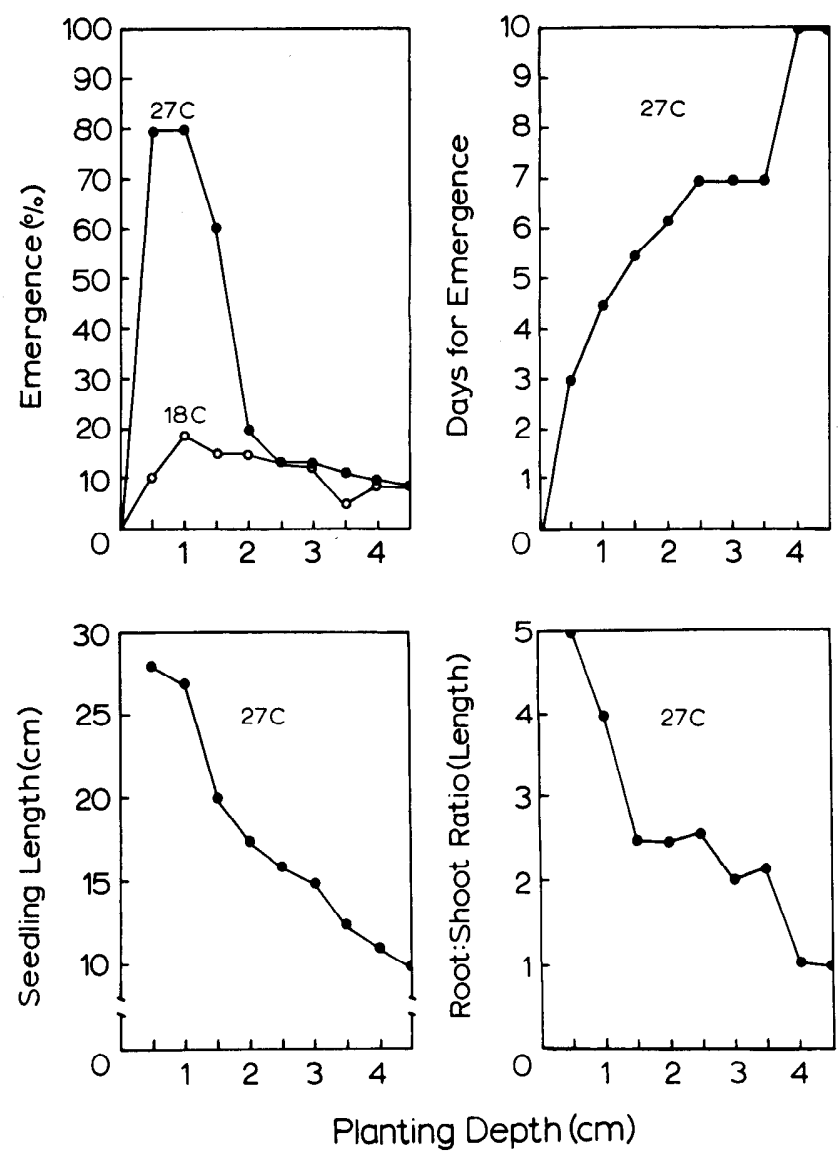

FIG. 1. Percentage emergence at two soil temperatures; and days required for emergence, seedling lengths and root:shoot ratios of honey mesquite seedlings at $27 \mathrm{C}$ soil temperature 21 days after planting at various depths in an Abilene silty clay loam.

The root:shoot ratio of seedling emerging from the $0.5 \mathrm{~cm}$ depth was $5: 1$. Root lengths decreased as seeding depth increased indicating that emergence of seedlings from below $1 \mathrm{~cm}$ occurred at the expense of root development. Although seedlings did not emerge from 5 to $6 \mathrm{~cm}$ deep at $27 \mathrm{C}$, most produced a radicle of 6 to $7 \mathrm{~cm}$ before dying. Those seedlings which did not emerge from soil at the low temperature produced radicles of about $4 \mathrm{~cm}$ before dying.

Direct relationships existed between planting date, soil tcmperature of the surface $(2.5 \mathrm{~cm})$ and seedling emergence in the nursery. Poor emergence from the March 6 planting (Fig. 2) was probably due to low soil temperatures in the planting zone from March 7 to 20. Maximum surface soil temperature reached $25 \mathrm{C}$ only 2 or 3 days and was less than $10 \mathrm{C}$ for 4 days. A noticeable increase in emergence resulted from March 20 plantings (Fig. 2). On 6 of the 10 days following the planting, the surface soil temperature was $25 \mathrm{C}$ or higher. Peak emergence on April 24 was preceded by 4 days and followed by 2 days of maximum soil temperatures around $25 \mathrm{C}$. In August, no trends in seedling

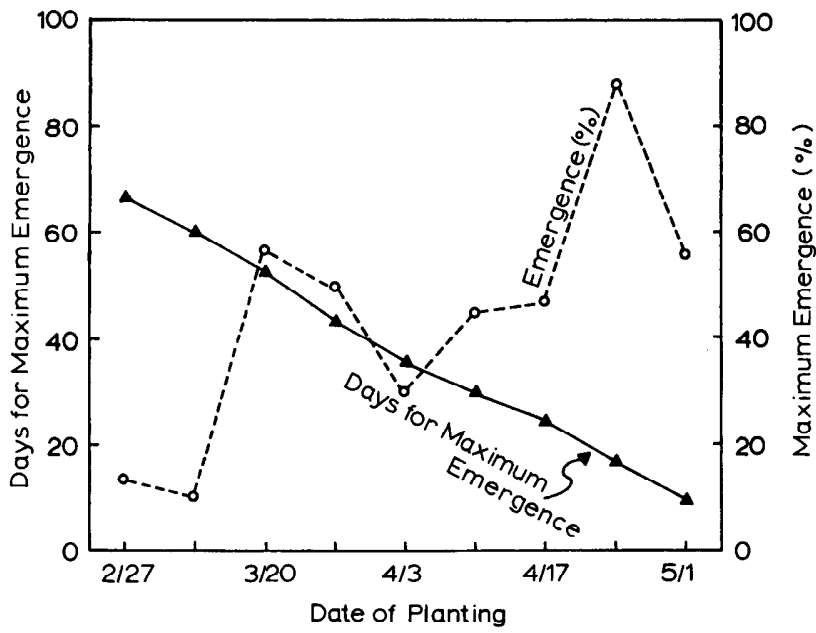

FIG. 2. Days required for maximum emergence and percentage maximum emergence of honey mesquite seedlings in a nursery after planting at various dates in 1969 in the Rolling Plains of Texas.

height, number of leaves per plant or nodes per stem regardless of planting date were noted. Average plant height was about $13 \mathrm{~cm}$ with an average of 20 nodes per stem.

Scarification is evidently the first requisite for germination of honey mesquite (Fisher et al., 1959) and may occur naturally by passage of seeds through the digestive systems of animals. Soil cover of scarified seeds may be the next most important factor. Honey mesquite seeds do not require soil cover to germinate, but do require a thin layer for seedling establishment. At the optimum depth and under favorable moisture conditions, maximum emergence in the field may be dependent upon soil temperature reaching about $25 \mathrm{C}$.

\section{Literature Cited}

Allred, B. W. 1949. Distribution and control of several woody plants in Oklahoma and Texas. J. Range Manage. 2:17-29.

Fischer, C. E., C. H. Meadors, R. Behrens, E. D. Robison, P. T. Marion, and H. L. Morton. 1959. Control of mesquite on grazing lands. Texas Agr. Exp. Sta. Bull. 935. 24 p.

Meyer, R. E., H. L. Morton, R .H. HaAs, E. D. Robison, AND T. E. Riley. 1971. Morphology and anatomy of honey mesquite. U. S. Dep. Agr. Tech. Bull. 1423. 186 p.

MarTIN, S. C. 1948. Mesquite seeds remain viable after 44 years. Ecology 29:393.

Scifres, C. J., J. H. Brock, and R. R. HAHN. 1971. Influence of secondary succession on honey mesquite invasion in North Texas. J. Range Manage. 24:206-210.

Scifres, C. J., AND R. R. HAHN. 1971. Response of honey mesquite seedlings to top removal. J. Range Manage. 24: 296-298.

Scifres, C. J., ANd J. H. Brock. 1969. Moisture-temperature interrelations in germination and early seedling development of honey mesquite. J. Range Manage. 22: 334-337. 
Scifres, C. J., ANd J. H. Brock. 1971. Thermal regulation Tschirley, F. H., and S. C. Martin. 1960. Germination of water uptake by germinating honey mesquite seeds. and longevity of velvet mesquite seed in soil. J. Range J. Range Manage. 24:157-158.

Manage. 13:94-97. 